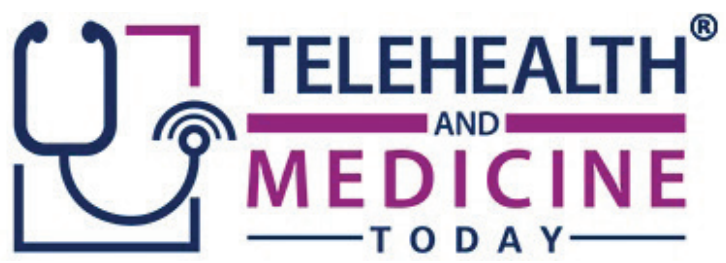

\title{
Telehealth: Legal and Ethical Considerations for Success
}

\author{
Claude J. Pirtle, Kathryn L. Payne, Brian C. Drolet
}

Affiliation: Vanderbilt University Medical Center, Nashville, TN, USA

Corresponding Author: Claude J. Pirtle, MD, MSACI, Department of Biomedical Informatics, Vanderbilt University, 2525 West End Avenue, Suite 1475, Nashville, TN 37203, USA, Email: claude.j.pirtle@vumc.org

Keywords: Barriers to Access, Ethical, Legal, Regulatory, Telehealth, Telemedicine

Section: Opinions, Perspectives, and Commentary on a current trend or issue impacting the sector

$\mathrm{T}$ he practice of medicine has advanced significantly from the bloodletting of the 18th century to a surgeon operating remotely through a robot from hundreds of miles away. ${ }^{1}$ Over the past decade, technology, and particularly telehealth, has become increasingly widespread in global health care delivery. ${ }^{2,3}$ Telehealth is a general term that describes the use of telecommunication technologies in support of clinical health care, education, and public health. ${ }^{4}$ Telehealth services include not only traditional video conferencing but also e-mail, remote patient monitoring devices, and even facsimile. ${ }^{5,6}$ Teleheath technology allows physicians and other providers to consult and assist with data interpretation and patient care regardless of geographic separation. For example, a specialty radiologist may read advanced imaging for a primary care physician in a remote area.

Many federal, state, and private insurers are beginning to recognize the technological advantages of telehealth and have instituted reimbursement of these services. In July 2018, the Centers for Medicare \& Medicaid Services (CMS) proposed extension of Medicare Telehealth coverage. ${ }^{7}$ This proposal expanded coverage for telehealth services and allows physicians to provide virtual home visits more easily. In fiscal year 2016 , over $12 \%$ of veterans received a portion of their care via a Veterans Affairs (VA) telehealth platform. ${ }^{8}$

Telehealth has gained significant traction in a number of health care service lines including neurology, behavioral health, and case management. Poststroke telehealth is a useful supplement to a patient's rehabilitation and recovery, particularly when combined with the communication of a health care professional. ${ }^{9}$

Telepsychiatry is a developing field in the world of telehealth as well. A recent review of telepsychiatry literature by Hubley et al. 
showed it was comparable to face-to-face delivery of mental health interventions and can be a cost-effective approach to improve access. ${ }^{10}$ Although telehealth has seen significant growth and may offer many potential benefits such as increased access to care providers, ${ }^{11}$ reduced health care costs and improved quality and continuity of care, ${ }^{6}$ there are a number of ethical, legal, and regulatory issues that surround this developing technology.

Telehealth pushes the boundaries of informed consent, justice, and provider competencies, as well as a number of professional regulatory domains. To begin with, telehealth users may have variable levels of experience and technical savviness. Therefore, risks associated with telehealth (e.g., miscommunication or incomplete examination of a patient) may not be recognized completely by the novice patient or proxy. ${ }^{12}$ As a result, telehealth challenges "what 'informed' [consent] means when new technologies require education about benefits and burdens associated with their use." ${ }^{13}$ This is especially true when users, either provider or patient, have limited understanding of the technology itself. Informing patients and ensuring their understanding about the scope of telehealth is critical. It is essential for individuals to understand both the strengths and limitations of this technology.

Although they may be most at need, patients in remote areas or those who are socioeconomically disadvantaged may not have access to this type of technology. ${ }^{14}$ Therefore, concerns for equitable distribution of care (i.e., justice) abound in the implementation of telehealth, particularly in impoverished remote areas that need it most. In 2016, 39\% of rural Americans (about 23 million people) lacked access to broadband Internet compared to only $4 \%$ of urban Americans. ${ }^{15}$ A 2019 article estimates 200,000 residents in the US state of Maine lack access to broadband Internet services, and the state government is exploring options to mitigate this potentially one billion dollar state problem. ${ }^{16}$ Other issues arise through economic disparity, including the cost of technological equipment. ${ }^{11}$ Thus, while technological advances may improve the communication of ailments and symptoms through video conferencing via high-speed interfaces or smartphones, individuals who need telehealth the most may not have the opportunity to use this medium.

Strides have been taken to narrow the connectivity gap. One source of improvement is the use of smart phone and mobile broadband technology to refine this area. Many government and private entities are working to improve rural Internet access. Two proposed legislative bills in the state of Maine would provide over one hundred million dollars for rural high speed Internet expansion. ${ }^{16}$ A number of private companies have chosen to specifically focus on this digital divide and deploy technology to improve broadband access by rural populations. ${ }^{17}$ AT\&T (the largest multichannel video service provider in the United States) has committed to offering high-speed Internet to more than 1.1 million hard-to-reach locations by 2020 and as of the end of 2018 has completed over half of their connectivity goal. ${ }^{18}$ However, possessing the latest technology to participate in telehealth, does not ensure improved utilization. It has been noted that indigent and rural populations, when compared with other populations with access to telehealth technology, have lower use rates. ${ }^{19}$

Despite benefits of telehealth, credentialing and licensure requirements represent significant access barriers for physicians. As of January 2018, the medical boards of 49 states plus Puerto Rico and the District of Columbia required that physicians be licensed in the state in which they are providing patient 
care and in which the patient is located. ${ }^{20}$ This not only causes a significant cost barrier to clinicians providing telehealth, but it also causes a significant access barrier. ${ }^{21}$ Even when a physician's license is valid, more barriers exist regarding practice privileges within different health care systems. Steps have begun on a federal level to curb this barrier. In the summer of 2018, the United States Department of Veteran Affairs expanded telehealth by allowing their health care providers to treat VA patients across state lines without a license in that state. ${ }^{22}$ The Interstate Medical Licensure Compact (IMLC) is an opportunity that allows an expedited pathway to licensure for physicians. At this time, the IMLC has a mutual agreement between 24 states. ${ }^{23}$ The creation of this compact is a significant step in the right direction for physicians to practice in multiple states. These continued efforts would not only increase access to care for a multitude of patient populations but also curb the financial burden on providers.

Telehealth technology also brings to light the importance of highly practiced communication skills in an effort to account for a shortage of visual cues. ${ }^{24}$ Therefore, communication competencies for providers need to be emphasized during and after training. With providers able to see patients in diverse and distant geographic regions, cultural competency is particularly relevant. Importantly, telehealth providers are now constrained to using only two of their five senses, and this is a fundamental change in the way of communicating and practicing medicine. Although limited evidence is available to show the effectiveness of specialized training in telehealth, multiple authors have made the case that telemedicine training would be beneficial for future providers. Pathipati et al. assert the importance of incorporating formal telemedicine into medical school curriculum, ${ }^{25}$ and Slovensky et al. outline a model promoting the skills needed to create an educational curriculum for clinicians who will use digital technology. ${ }^{26}$ The Association of American Medical Colleges reported that in the 2016-2017 academic year, $58 \%$ of medical schools in the United States and Canada included telemedicine in their coursework. ${ }^{27}$ With the continued evolution of technology and the importance of remote care, training in this domain will be an essential component of medical education. To help combat deficiencies in supplying telehealthcare, some nurse practitioner programs have recognized these weaknesses and begun to immerse students into clinical settings or provided practical experience to learn more about extending this type of health care. ${ }^{28}$

Telehealth technology offers the ability to have an in-depth, two-way conversation with an individual hundreds of miles away. In a recent article entitled, "Doctor on video screen told a man he was near death, leaving relatives aghast," the ethics of discussing a shocking prognosis in person has been highlighted. This is far from a contemporary idea in medicine and has been considered essential since the time of Hippocrates. In a 2010 study, $18 \%$ of patients were told of a cancer diagnosis over the phone..$^{29}$ This brings into questionshould the discussion of bad news always be in person? According to a 2016 survey, most patients think the answer is "yes." 30

An alternative to delivering bad news by telemedicine alone may be to include an onsite colleague who can provide emotional support. This option uses high tech, as well as high touch through an in-person surrogate. This could prevent the family and significant others journeying hours into a busy academic center only to hear the difficult news and 
shortly after having to leave to return home. Tele-technology is merely a tool to disclose this information. It may be time to push not only the limits of best practice but also develop solutions that allow a patient to feel comfortable and welcomed with human touch while still allowing for technology.

Telehealth is a technology with the potential to allow numerous improvements in health care; however, ethical, regulatory, and technical considerations must be evaluated and managed to address the drawbacks. A governance model that is standardized across all state and federal levels could alleviate some legal concerns, particularly regarding credentialing and licensure. Incorporating ethical and technical training around telehealth into medical and nursing education will prepare future providers for the inevitable remote health care to be provided through digital communication. This training should be comprehensive of not only medical expertise but also communicating with empathy. Finally, broadening the education of consumers on the potential robustness and limitations of telehealth will allow individuals to take part in a potentially lifesaving technology. This is a technology that is headed for prime time.

\section{Funding Statement}

This work was not supported by grants or awards.

\section{Conflict of Interest}

Claude J. Pirtle, MD, MSACI, is a member of the content review board of Telehealth and Medicine Today. The authors have no other conflicts of interest.

\section{Contributors Contributions}

All authors equally contributed to this publication.

\section{REFERENCES}

1. The surgeon who operates from $400 \mathrm{~km}$ away. 2014 [cited 2018 Sep 25]. Available from: http:/www.bbc.com/ future/story/20140516-i-operateon-people-400km-away

2. Wilson LS, Maeder AJ. Recent directions in Telemedicine: Review of trends in research and practice. Healthc Inform Res. 2015;21(4):213-22. https://doi.org/10.4258/ hir.2015.21.4.213

3. Holt B, Faraklas I, Theurer L, Cochran A, Saffle JR. Telemedicine use among burn centers in the United States: A survey. $J$ Burn Care Res. 2012;33(1):157-62. https:// doi.org/10.1097/BCR.0b013e31823d0b68

4. Moffatt JJ., Eley DS. The reported benefits of telehealth for rural Australians. Aust Health Rev. 2010;34:276-81.

5. What is telehealth? How is telehealth different from telemedicine? [cited 2018 Oct 2]. Available from: https://www. healthit.gov/faq/what-telehealth-howtelehealth-different-telemedicine

6. Majerowicz A, Tracy S. Telemedicine: Bridging gaps in healthcare delivery. J AHIMA . 2010;81(5):52-3, 56.

7. Mullaney T. CMS proposes expanded medicare telehealth coverage. 2018 [cited 2018 Oct 5]. Available from: https:// homehealthcarenews.com/2018/07/cmsproposes-expanded-medicare-telehealthcoverage/

8. VA telehealth services-Fact sheet. [cited 2019 Jan 3]. Available from: https://www. va.gov/COMMUNITYCARE/docs/news/ VA_Telehealth_Services.pdf

9. Lutz BJ, Chumbler NR, Lyles T, Hoffman N, Kobb R. Testing a home-telehealth programme for US veterans recovering from stroke and their family caregivers. Disabil Rehabil. 2009;31(5):402-9. https:// doi.org/10.1080/09638280802069558

10. Hubley S, Lynch SB, Schneck C, Thomas M, Shore J. Review of key telepsychiatry outcomes. World $J$ Psychiatry. 2016;6(2):269-82. https://doi. org/10.5498/wjp.v6.i2.269 
11. Cao MD, Shimizu S, Antoku Y, et al. Emerging technologies for telemedicine. Korean J Radiol. 2012;13(Suppl 1):S21-30.

12. Demiris G, Oliver DP, Courtney KL. Ethical considerations for the utilization of telehealth technologies in home and hospice care by the nursing profession. Nurs Adm Q. 2006;30(1):59-61.

13. Kaplan B, Litewka S. Ethical challenges of telemedicine and telehealth. Camb Q. Healthc Ethics. 2008 Fall;17(4):401-16. https://doi.org/10.1017/S0963180108080535. PubMed PMID: 18724880.

14. Langarizadeh $\mathrm{M}$, Moghbeli F, Aliabadi A. Application of ethics for providing telemedicine services and information technology. Med Arch. 2017;71(5):351-5. https://doi.org/10.5455/ medarh.2017.71.351-355

15. 2016 broadband progress report. [cited 2018 Sep 25]. Available from: https://www.fcc. gov/reports-research/reports/broadbandprogress-reports/2016-broadband-progressreport

16. Anderson JC. Maine's rural broadband may get a boost. 2019 [cited 2019 Mar 18]. Available from: https://www.pressherald. com/2019/02/14/advocates-like-the-chancesof-bills-expanding-rural-broadband-access

17. O'Dowd E. Wireless broadband improvements key to rural telehealth. 2017 [cited 2019 Mar 18]. Available from: https://hitinfrastructure.com/news/wirelessbroadband-improvements-key-to-ruraltelehealth

18. Scarborough E. Connecting rural America: Delivering fixed wireless internet through new technologies. 2018 [cited 2019 Mar 18]. Available from: https://about.att.com/ story/2018/fixed_wireless_rural_america. html

19. Park J, Erikson C, Han X, Iyer P. Are state telehealth policies associated with the use of telehealth services among underserved populations? Health Aff. 2018;37(12):2060-8.

20. Federation of State Medical Boards. Telemedicine policies by state. 2018 [cited 2018 Sep 25]. Available from: http://www. fsmb.org/globalassets/advocacy/key-issues/ telemedicine_policies_by_state.pdf

21. LeRouge C, Garfield MJ. Crossing the telemedicine chasm: Have the U.S. barriers to widespread adoption of telemedicine been significantly reduced? Int J Environ Res Public Health. 2013;10(12):6472-84. https://doi.org/10.3390/ijerph10126472

22. VA expands telehealth by allowing health care providers to treat patients across state lines. [cited $2018 \mathrm{Sep} 25$ ]. Available from: https://www.va.gov/opa/pressrel/ pressrelease.cfm? $\mathrm{id}=4054$

23. The IMLC. [cited 2019 Feb 14]. Available from: https://imlcc.org

24. Morony S, Weir K, Duncan G, Biggs J, Nutbeam D, Mccaffery KJ. Enhancing communication skills for telehealth: Development and implementation of a Teach-Back intervention for a national maternal and child health helpline in Australia. BMC Health Serv Res. 2018;18:162. https://doi.org/10.1186/ s12913-018-2956-6

25. Pathipati AS, Azad TD, Jethwani K. Telemedical education: Training digital natives in telemedicine. $J$ Med Internet Res. 2016;18(7):e193. https://doi.org/10.2196/ jmir.5534

26. Slovensky DJ, Malvey DM, Neigel AR. A model for mHealth skills training for clinicians: Meeting the future now. Mhealth. 2017;3:24. https://doi.org/10.21037/ mhealth.2017.05.03

27. Warshaw R. From bedside to webside: Future doctors learn how to practice remotely. 2018 [cited 2018 Nov 11]. Available from: https://news.aamc.org/ medical-education/article/future-doctorslearn-practice-remotely/

28. Rutledge CM, Kott K, Schweickert PA, Poston R, Fowler C, Haney TS. Telehealth and eHealth in nurse practitioner training: Current perspectives. Adv Med Educ Pract. 2017;8:399-409. https://doi.org/10.2147/ AMEP.S116071

29. Figg WD, Smith EK, Price DK, et al. Disclosing a diagnosis of cancer: 
Where and how does it occur?. J Clin Oncol. 2010;28(22):3630-5. https://doi.org/10.1200/ JCO.2009.24.6389

30. Wicklund E. Docs prefer "The human touch" to telemedicine when delivering bad news. 2016 [cited 2019 Mar 18]. Available from: https://mhealthintelligence.com/news/ docs-prefer-the-human-touch-totelemedicine-when-delivering-badnews
Copyright Ownership: This is an open access article distributed in accordance with the Creative Commons Attribution Non Commercial (CC BY-NC 4.0) license, which permits others to distribute, adapt, enhance this work non-commercially, and license their derivative works on different terms, provided the original work is properly cited and the use is noncommercial. See: http://creativecommons. org/licenses/by-nc/4.0. 